\title{
Cation Redistribution along the Spiral of Ni-Doped Phyllosilicate Nanoscrolls: Energy Modelling and STEM/EDS Study
}

Andrei A. Krasilin, ${ }^{a, b, *}$ Ekaterina K. Khrapova, ${ }^{a}$ Alexandre Nominé, ${ }^{b, c}$ Jaafar Ghanbaja, ${ }^{c}$ Thierry Belmonte, ${ }^{c}$ and Victor V. Gusarov, ${ }^{a}$

a Laboratory of New Inorganic Materials Ioffe Institute 26 Politekhnicheskaya St., St. Petersburg, 194021, Russia

${ }^{b}$ Dr. A. A. Krasilin, Dr. A. Nominé Department of Nanophotonics and Metamaterials ITMO University 49 Kronverksky Pr., St. Petersburg, 197101, Russia

${ }^{c}$ Dr. A. Nominé, Dr. J. Ghanbaja, Prof. T. Belmonte Institut Jean Lamour, UMR CNRS 7198 Université de Lorraine Campus Artem, 2 allée André Guinier, Nancy 54000, France

E-mail: ikrasilin@mail.ioffe.ru

\section{KEYWORDS}

Crystal growth ; Doping ; Electron microscopy ; Hydrothermal synthesis ; Phyllosilicates

\begin{abstract}
Here, we study the stress-induced self-organization of $\mathrm{Mg}^{2+}$ and $\mathrm{Ni}^{2+}$ cations in the crystal structure of multiwalled $\left(\mathrm{Mg}_{1-x}, \mathrm{Ni}_{\mathrm{x}}\right)_{3} \mathrm{Si}_{2} \mathrm{O}_{5}(\mathrm{OH})_{4}$ phyllosilicate nanoscrolls. The phyllosilicate layer strives to compensate size and surface energy difference between the metal oxide and silica sheets by curling. But as soon as the layer grows, the scrolling mechanism becomes a spent force. An energy model proposes secondary compensation of strain: two cations distribute along the nanoscroll spiral in accordance with preferable radii of curvature. To reveal this, we study synthetic $\left(\mathrm{Mg}_{1-x}, \mathrm{Ni}_{x}\right)_{3} \mathrm{Si}_{2} \mathrm{O}_{5}(\mathrm{OH})_{4}$ nanoscrolls by the scanning transmission electron microscopy/energy-dispersive $\mathrm{X}$-ray spectroscopy (STEM/EDS) technique. For a number of scrolls, we have found indeed a change of Ni concentration with increase in distance from the nanoscroll central axis. The concentration gradient, according to our estimates, can reach 50 at.\% over $25 \mathrm{~nm}$ of the wall thickness.
\end{abstract}




\section{Introduction}

Some of 1:1 phyllosilicates and clays possess a very intriguing feature, which consists in spontaneous curling of crystalline layer with a formation of nanotubes and nanoscrolls. Three of the most known representatives are chrysotile $\mathrm{Mg}_{3} \mathrm{Si}_{2} \mathrm{O}_{5}(\mathrm{OH})_{4}$,[1-3] halloysite $\mathrm{Al}_{2} \mathrm{Si}_{2} \mathrm{O}_{5}(\mathrm{OH})_{4},[4-6]$ and imogolite $\mathrm{Al}_{2} \mathrm{SiO}_{3}(\mathrm{OH})_{4}$. [7,8] Because of wide occurrence in nature, their tubular shape had been revealed decades before the carbon [9-10] and chalcogenide[11,12] nanotubes discoveries. Such hydrosilicate layers consist of brucite-like or gibbsite-like octahedral sheet bonded to a $\mathrm{SiO}_{2}$ tetrahedral sheet. In the case of imogolite, single $\mathrm{SiO}_{4}$ tetrahedra fit into voids of the same gibbsite-like sheet. Size difference between the sheets (or between the void and the tetrahedra) creates internal stress of the whole layer and initiates its curling.

Single-walled and multi-walled nanotubes and nanoscrolls formed by this process have a range of interesting properties and related applications. The inner channel grants large specific surface area (up to $400 \mathrm{~m}^{2} / \mathrm{g}$ )[5,13] as well as active sites for adsorption[14,15] and encapsulation of functional substance.[16,17] The outer and inner hydrosilicates surfaces saturated with $\mathrm{OH}$ groups can be modified by various organic compounds as well as be decorated by metallic or oxide phases.[18,19] High aspect ratio affects on particles aggregation: entangling of nanotubes and nanoscrolls is used for production of self-supported and composite membranes.[20,21] Individual nanoscrolls demonstrate good mechanical properties, [22,23] which are appropriate for reinforcement of polymer composites. Change of $\mathrm{Mg}$ by a delement like Ni enhances magnetic properties of the particles.[ 24,25] The delement can then be reduced from the silicate matrix by hydrogen in order to produce composite materials with catalytic activity.[26,27]

Cations substitutions in the phyllosilicate layer change size and morphology of the resulting nanotubes and nanoscrolls. In the case of chrysotile to date there are series of reports on change of $\mathrm{Mg}$ and (or) $\mathrm{Si}$ by $\mathrm{Fe},[24,28,29] \mathrm{Ni},[30-32] \mathrm{Ti},[33,34]$ and $\mathrm{Ge} .[35]$ Halloysite and imogolite were successfully doped by $\mathrm{Ge}[5,36]$ and Fe[37] as well.

In this paper we would like to drive an attention to some feature which can be observed during partial substitution by a guest cation. Thill et al.[36] have claimed that in the $\mathrm{Al}_{2}\left(\mathrm{Si}_{x}, \mathrm{Ge}_{1-\mathrm{x}}\right) \mathrm{O}_{3}(\mathrm{OH})_{4}$ system single-walled and double-walled imogolite nanotubes were formed at $x=1$ and $x=0$, correspondingly. If the value was $0<x<1-\mathrm{i}$. e. both $\mathrm{Si}$ and $\mathrm{Ge}$ cations were present - triple-walled nanoscrolls were formed. Bloise et al.[30] have found that considerable amounts of particles with telescopic and conical morphology can be obtained by hydrothermal treatment of $\mathrm{Ni}$-doped forsterite.[38] The same situation was observed in case of Fe-containing precursor.[28] Krasilin et al. have showed $[39,40]$ that conical scrolls content has a maximum provided that both $\mathrm{Mg}$ and $\mathrm{Ni}$ are present in $\left(\mathrm{Mg}_{1-x}, \mathrm{Ni}_{\mathrm{x}}\right)_{3} \mathrm{Si}_{2} \mathrm{O}_{5}(\mathrm{OH})_{4}$ nanoscrolls with chrysotile structure.

These features could owe to a sort of inhomogeneity in cations distribution between the particles as well as within the layer. Krasilin et al. have demonstrated[41] that $\mathrm{Mg} / \mathrm{Ni}$ ratio changes in correlation with the number of layers (outer diameter) of the nanoscroll. Here we attempt to deepen the study of chemical composition of individual $\left(\mathrm{Mg}, \mathrm{Ni}_{3}\right)_{3} \mathrm{Si}_{2} \mathrm{O}_{5}(\mathrm{OH})_{4}$ multi-walled nanoscrolls using transmission electron microscopy in order to reveal a consistency in cations distribution along the phyllosilicate layer.

\section{Results and Discussion}

\subsection{Energy Effect of Cation Redistribution}


In the previous studies[32,40,42] we have developed an energy model of scrolling of a 1:1 phyllosilicate flat layer with chrysotile structure, which is based on the models proposed elsewhere. $[36,43,44]$ Here we would like to pay attention to some chemical composition features that could exist in case several cations constitute the phyllosilicate octahedral sheet. First, let us consider the layer as a continuous media of two chemically bonded sheets (Figure 1) of $\mathrm{MeO}_{6}$ octahedra and $\mathrm{SiO}_{4}$ tetrahedra. These two sheets possess slightly different sizes $b_{\mathrm{o}}$ and $b_{\mathrm{t}}$ that result in an appearance of an internal stress in the layer. Its bending and scrolling are one of the effective relaxation paths.

Full compensation of the size difference between the sheets is achieved at the following radius of curvature:

$$
r_{0} \cong \frac{h b_{0}+b_{\mathrm{t}}}{4}
$$

where $h$ is the layer thickness. This radius can be determined in a result of diffraction studies $[46,47]$ or structure optimization.[48] For the case of $\mathrm{Mg}_{3} \mathrm{Si}_{2} \mathrm{O}_{5}(\mathrm{OH})_{4}$ nanoscrolls these approaches yield $r_{0, \mathrm{Mg}}$ value around $8.8 \mathrm{~nm}$.

Substitution of ions in the crystal structure, obviously, will affect $b_{0}, b_{\mathrm{t}}$ and $r_{0}$ values. Figure 1 shows that the structure of the octahedral sheet is mostly equivalent to that of layered hydroxide, for example, $\mathrm{Mg}(\mathrm{OH})_{2}$. If the guest cation $\mathrm{Me}$ can form the layered hydroxide of similar structure, the $r_{0, \mathrm{Me}}$ value can be recalculated on the basis of cell parameters of these hydroxides, assuming negligible $b_{\mathrm{t}}$ and $h$ change:

$$
r_{0, \mathrm{Me}}=\frac{h}{4} \frac{b_{0, \mathrm{Me}}\left(r_{0, \mathrm{Mg}}+h / 4\right)+b_{0, \mathrm{Mg}}\left(r_{0, \mathrm{Mg}}-h / 4\right)}{b_{0, \mathrm{Me}}\left(r_{0, \mathrm{Mg}}+h / 4\right)-b_{0, \mathrm{Mg}}\left(r_{0, \mathrm{Mg}}-h / 4\right)}
$$

For the case of $\mathrm{Ni}_{3} \mathrm{Si}_{2} \mathrm{O}_{5}(\mathrm{OH})_{4}$ nanoscrolls this equation yields $r_{0, \mathrm{Ni}}=15 \mathrm{~nm}$.[32]

The $r_{0}$ value is important, but it is not the only factor that governs the scrolling process. To understand that it is sufficient to look at the morphology of $\mathrm{Mg}_{3} \mathrm{Si}_{2} \mathrm{O}_{5}(\mathrm{OH})_{4}$ and $\mathrm{Ni}_{3} \mathrm{Si}_{2} \mathrm{O}_{5}(\mathrm{OH})_{4}$ nanoscrolls: they never form single-walled nanotubes of 18 and $30 \mathrm{~nm}$ in diameter except very initial stages of growth. $[3,49]$ On the contrary, they are multi-walled. This issue can be explained by the following energy model.

We consider an energy effect $(\mathrm{J} / \mathrm{mol})$ of the scrolling process consisting of three components:

$$
E=\frac{1}{v}\left(E_{s}+\Sigma_{s}+U_{a}\right)
$$

where $v$ is a quantity of substance; $E_{\mathrm{s}}$ is a strain energy change; $\Sigma_{\mathrm{s}}$ is a surface energy change; $U_{\mathrm{a}}$ is an adhesion energy change. Each of the three energy components are differences between energy values of scrolled and flat phyllosilicate layers.

The adhesion energy differs from zero only if the number of layers $n$ in the scroll is more than 1. The $U_{a}$ value is proportional to the surface area of contact between two adjacent wraps. It can be calculated by integration over the Archimedean spiral:

$$
U_{\mathrm{a}}=u_{\mathrm{a}} L_{2} \int_{0}^{2 \pi(n-1)} \sqrt{f^{2}+\left[r_{\text {In }}+(h+t) / 2+f \varphi\right]^{2}} d \varphi
$$


where $u_{\mathrm{a}}$ is a specific adhesion energy; $L_{2}$ is the nanoscroll length; $f=(h+t) / 2 \pi$ is the spiral constant; $t$ is the interlayer distance; $r_{\text {in }}$ is inner (starting) radius of the spiral; $\varphi$ is an angle coordinate.

Surface energy of the scrolled state of the layer can be obtained by the analogical procedure taking into the account all the surfaces of the layer:

$$
\Sigma_{\mathrm{s}}^{e}=L_{2}\left(\sigma_{\text {out }} L_{1, \text { out }}+\sigma_{\text {in }} L_{1, \text { in }}\right)+2 h\left(\sigma_{1} L_{1}+\sigma_{2} L_{2}\right)
$$

where $\sigma_{\text {out }}, \sigma_{\text {in, }} \sigma_{1}$, and $\sigma_{2}$ are specific surface energies of outer surface, inner surface, ends and edges of the scroll; $L_{1, \text { out }}, L_{1, \text { in }}$ are lengths of coils formed by outer and inner surfaces; $L_{1}$ is coil length at middle of the layer. For the flat layer these lengths are equal.

Assuming small bending, strain energy of the scroll is proportional to squared difference of curvatures:

$$
E_{s}^{\infty}=\frac{D_{s}}{2} L_{2} \int_{0}^{2 \pi n}\left(\frac{1}{r(\varphi)}-\frac{1}{r_{0}}\right)^{2} \sqrt{f^{2}+r^{2}(\varphi)} \mathrm{d} \varphi
$$

where $D_{\mathrm{s}}$ is bending stiffness, and $\mathrm{r}(\varphi)$ is current radius of curvature. According to the general equation of the Archimedean spiral:

$$
r(\varphi)=r_{\ln }+f \varphi
$$

The flat layer has zero curvature, and the equation (6) simplifies:

$$
E_{s}^{-}=\frac{D_{s}}{2} \frac{L_{1} L_{2}}{r_{0}^{2}}
$$

These basic equations allow us to determine preferable size parameters - length, outer and inner diameter - of cylindrical nanoscroll of certain mass, which includes only one type of cation in the octahedral sheet (for example, $\mathrm{Mg}^{2+}$ or $\mathrm{Ni}^{2+}$, see Figure 1). If the sheet contains two or more cations, all the parameters in the equation should be estimated (as a first approximation) on the basis of an interpolation procedure.

Two cations can be randomly or nonrandomly distributed in the layer. The latter means that parameters like $D_{\mathrm{s}}, \sigma_{\mathrm{i}}, u_{\mathrm{a}}$, and $r_{0}$ will become coordinate-dependent. Further on we will concentrate on the analysis of the strain energy contribution (6) and (8) only for the case of substitution of $\mathrm{Mg}^{2+}$ by $\mathrm{Ni}^{2+}$ assuming negligible surface and adhesion energy change. This approximation is justified by close бi values of the corresponding oxides.[32]

The flat layer, as it seems, does not get any energy preference from nonrandom distribution (redistribution) of the cations (8). Nevertheless, it could affect steadiness of the scrolling process and lead to formation of noncylindrical scrolls because of different $r_{0}$ values in different places of the layer. In case of cylindrical scroll, redistribution along cylinder length $L_{2}$ does not cause strain decrease (6). On the contrary, redistribution of $\mathrm{Mg}^{2+}$ and $\mathrm{Ni}^{2+}$ along the length $L_{1}$ could cause minimization of the squared difference under the integral:

$$
\frac{1}{r_{\text {In }}+f \varphi}-\frac{1}{r_{0}(\varphi)} \rightarrow 0
$$


To achieve this, the $r_{0}(\varphi)$ value should closely follow current radius of curvature $r(\varphi)$. Because $r(\varphi)$ is a linear function of $\varphi(7)$, the form of $r_{0}(\varphi)$ should be close to straight line as well.

We try to reveal this dependence by electron microscopy study of $\mathrm{Ni}$ concentration changes in single $\left(\mathrm{Mg}, \mathrm{Ni}_{3} \mathrm{Si}_{2} \mathrm{O}_{5}(\mathrm{OH})_{4}\right.$ nanoscrolls.

\subsection{PXRD and SEM/EDS}

Figure 2 shows PXRD patterns of initial composition and its hydrothermal treatment product. Co-precipitation reaction in presence of amorphous $\mathrm{SiO}_{2}$ yields poorly crystalline phase with layered structure. Its hydrothermal treatment leads to formation of a phase with a set of reflections corresponding to those of $\# 10-381 \mathrm{Mg}_{3} \mathrm{Si}_{2} \mathrm{O}_{5}(\mathrm{OH})_{4}$ or \#49-1859 $\mathrm{Ni}_{3} \mathrm{Si}_{2} \mathrm{O}_{5}(\mathrm{OH})_{4}$. An isostructural compound which would include both $\mathrm{Mg}^{2+}$ and $\mathrm{Ni}^{2+}$ ions is absent in the database. Hydrothermal treatment product possesses smaller interlayer period in comparison with that of the initial composition, probably because of removal of excessive amount of water molecules between the layers during crystal growth. PXRD does not reveal any other crystalline phases in the samples.

Table 1 demonstrates element composition of the hydrothermal treatment product measured by conventional SEM/EDS. Average Ni concentration $C_{\mathrm{Ni}}$ in the sample is a bit higher than the estimated one (50 at.\%), as a consequence, the ratio $R$ is higher than 1.5. Nevertheless, measured values coincide with the estimated ones within error.

\subsection{TEM Study}

Figures 3a-e represent different nanoscroll morphologies that are formed under hydrothermal conditions.

First group consists of aggregates of small scrolls up to $30 \mathrm{~nm}$ in diameter and $100-200 \mathrm{~nm}$ in length, despite their tubular form may not be always recognizable. Second group includes separate cylindrical and conical scrolls with outer diameter in the 30-70 nm range and length reaches up to several microns. It seems that a kind of attachment mechanism [50] can play an important role in the formation of these particles. Figures $3 b-e$ show some of the particles which probably exhibit this type of growth. Also, there are scrolls whose outer diameters overcome $100 \mathrm{~nm}$. Often, they have telescopic morphology (Figure 3c). Their outer diameter values are not usual for the case of pure Mg-based and $\mathrm{Ni}$-based phyllosilicate nanoscrolls, [32] and it can be related with simultaneous $\mathrm{Mg}^{2+}$ and $\mathrm{Ni}^{2+}$ presence in the system. Thill et al.[36] have reported diameter increase for the case of Ge-doped imogolite as well. The inner diameter of scrolls falls within the range 6-12 $\mathrm{nm}$ range. The inner diameter decreases with increase of the outer diameter value in consistency with the previous studies.[ 41]

We measured an interlayer period by analyzing a grey level profile of the TEM image (Figure 4). No correlation between the period and the distance from centre was found. Weight average value of the period was $0.72 \mathrm{~nm}$, and it fluctuated in the range 0.68 to $0.78 \mathrm{~nm}$. Mean d-spacing of the (002) X-ray peak was $0.73 \mathrm{~nm}$.

For the case of $\mathrm{Mg}_{3} \mathrm{Si}_{2} \mathrm{O}_{5}(\mathrm{OH})_{4}$ nanotubes Foresti et al.[1] have reported $0.734 \mathrm{~nm}$ d-spacing, and White et al.[51] have reported around $0.7 \mathrm{~nm}$ for $\mathrm{Ni}_{3} \mathrm{Si}_{2} \mathrm{O}_{5}(\mathrm{OH})_{4}$ nanotubes. Alvarez- Ramírez et al.[52] also have noted that the $d$-spacing of $\mathrm{Ni}_{3} \mathrm{Si}_{2} \mathrm{O}_{5}(\mathrm{OH})_{4}$ nanotubes varies in the range 0.75 to 0.85 $\mathrm{nm}$ depending on the number of layers. The observed variation can be related with different degree of layers hydration, which should increase $d$-spacing value. Taking into the account this feature, it is hard to reveal a probable effect of $d$-spacing change due to $\mathrm{Mg}^{2+}$ and $\mathrm{Ni}^{2+}$ redistribution, which should occur because of their different ionic radii. 


\subsection{STEM/EDS Study}

As a first attempt we determined $\mathrm{Ni}$ concentration in one nanoscroll with step variation of outer diameter (Figure 5). Except two areas, change of the $C_{\mathrm{Ni}}$ value stands in correlation with the outer diameter, although the its spread is only 3 at.\%. Note all $C_{\mathrm{Ni}}$ values in each of the areas is lower than that measured by conventional SEM/EDS (Table 1). On the other hand, we should not omit some systematic shift between the values obtained by the two techniques. We have showed[21] that Ni concentration in small particles is almost equal to the initial concentration set at co-precipitation stage. For bigger scrolls there was a shift of concentration which depended on their number of layers, or wall thickness. Here, we can observe this feature even within the single scroll.

Figure 6 shows the results of $\mathrm{Ni}$ concentration measurement by a line scan procedure. One can see an almost double increase of apparent $\mathrm{Ni}$ concentration with distancing from the nanoscroll central axis. The value drops down beyond the nanoscroll outer radius. Mean value of apparent concentration is 53 at.\%. The reconstruction procedure (see Methods section) demonstrates that first layers of the nanoscroll contain around 10 at.\% of $\mathrm{Ni}$. The concentration grows linearly at subsequent layers (distance from centre). Line scan EDS mode brings considerable damage to the nanoscroll, so it is more reliable to collect and process EDS maps. Figure 7 shows the results of Ni concentration profile measurement carried out by this approach. Average value of apparent concentration is 39 at.\%. The $\mathrm{CNi}$ value, as it was in the previous case, decreases with decrease in the distance from the nanoscroll centre, but here a behavior of the reconstructed CNi profile is more complex. This may be related to specific conditions of the nanoscroll growth or with close presence of other particles, which could distort the EDS results.

The last case showed in Figure 8 is a result of EDS mapping procedure carried out at higher magnification. We divided the nanoscroll map into series of $2 \mathrm{~nm}$ slices parallel to the nanoscroll axis (see Figure SI5 for details). Average apparent $\mathrm{Ni}$ concentration is 44 at.\%. The reconstructed concentration profile shows that, again, the CNi value gradually increases in the direction from inner layers to outer ones.

\subsection{Redistribution Mechanism}

We have demonstrated several cases of $\mathrm{Ni}$ concentration change with change of the layer curvature, which is equivalent to increase in distance from the nanoscroll centre. It can be revealed by different modes of STEM/EDS analysis, including measurement of average concentration in the "tube in tube" particle (Figure 5), line scan perpendicular to the nanoscroll (Figure 6), and processing of EDS maps (Figure 7 and 8).

We suppose that the effect of $\mathrm{Mg}^{2+}$ and $\mathrm{Ni}^{2+}$ ions redistribution can take place during the nanoscroll growth (Figure 9a). The scroll that has been just formed accounts only several layers in its structure with a radius of curvature close to $\mathrm{r} 0$ for given $\mathrm{Ni}$ concentration (around 50 at.\%). Under hydrothermal conditions nanoscroll begins to grow by virtue of species sedimentation on the outer and on the inner surface, and by stacking of adjacent scrolls (Figure 9a). At this stage, the redistribution can occur: layers with $r(\varphi)<r_{0, \mathrm{Mg}}$ are more favorable for Mg-rich species, and layers with $r(\varphi)>r_{0, \mathrm{Ni}}$ are more suitable for Ni-rich species. Layers with $r \mathrm{M}_{\mathrm{Mg}}<r(\varphi)<r_{0, \mathrm{Ni}}$ are situated in the intermediate zone. Assuming $r_{0}(\varphi)$ can be converted to $C_{\mathrm{Ni}}(\varphi)$ on the basis of the additivity rule, maximum Ni concentration change with increase in distance from centre should be from 0 at. $\%$ at $8.8 \mathrm{~nm}$ up to 100 at. $\%$ at $15 \mathrm{~nm}$ (dashed line on Figure 9b).

Solid lines obtained by approximation of reconstructed $C_{\mathrm{Ni}}$ values (see Figures 6-8) deviate from the theoretically proposed line. First and foremost, real nanoscrolls have inner and outer radii, 
different from the ideal situation ( $r_{0, \mathrm{Mg}}$ as the inner radius, and $r_{0, \mathrm{Ni}}$ as the outer one). As a consequence, $\mathrm{Ni}$ concentration profile can spread between the actual radii, and the slope decreases. Second reason of slope decrease is that the energy model does not take into account kinetic hindrances which could accompany the nanoscroll growth process. Third, other energy components (see equations (3)-(5)) can play a part in the redistribution process sophisticating the $C_{\mathrm{Ni}}(\varphi)$ behavior. Besides possible contribution of surface energy (see equation (5)) a kind of configuration entropy could act against cations redistribution.

\section{Conclusions}

To summarize, here we demonstrate both theoretical and experimental basis for $\left(\mathrm{Mg}_{1-}\right.$ $\left.{ }_{x}, \mathrm{Ni}_{x}\right)_{3} \mathrm{Si}_{2} \mathrm{O}_{5}(\mathrm{OH})_{4}$ phyllosilicate nanoscroll to redistribute $\mathrm{Mg}^{2+}$ and $\mathrm{Ni}^{2+}$ cations along the spiral in order to minimize an excessive internal stress. The stress originates from size difference between octahedral and tetrahedral sheets of the layer. In this particular example, $\mathrm{Mg}^{2+}$ having larger ionic radius $(720 \mathrm{pm})$ concentrates in the inner layers of the scroll, whereas $\mathrm{Ni}^{2+}(690 \mathrm{pm})$ prefers the outer layers of smaller curvature. This redistribution can occur during the nanoscroll recrystallization process under hydrothermal conditions by selective sedimentation of $\mathrm{Ni}$-rich and $\mathrm{Mg}$-rich species on the outer and on the inner surfaces of the scroll, correspondingly. According to the energy model, concentration change should be close to linear function of the radius of curvature (of angle). Despite the need of further theoretical development, conclusions driven here should be valid also for a more general case of cations substitutions in octahedral and/or tetrahedral sheets of curved hydrosilicates like chrysotile, halloysite, and imogolite.

\section{Experimental Section}

\section{$\left(\mathrm{Mg}_{1-\mathrm{x}}, \mathrm{Ni}_{\mathrm{x}}\right)_{3} \mathrm{Si}_{2} \mathrm{O}_{5}(\mathrm{OH})_{4}$ Nanoscroll Synthesis}

Hydrosilicate nanoscrolls with estimated $x=0.5$ and $(\mathrm{Mg}+\mathrm{Ni}) / \mathrm{Si}=1.5$ molar ratio were synthesized by a hydrothermal technique. On the first step, initial composition was prepared via reverse coprecipitation of $\mathrm{Mg}(\mathrm{OH})_{2}$ and $\mathrm{Ni}(\mathrm{OH})_{2}$ from $400 \mathrm{ml}$ of $1 \mathrm{M} \mathrm{MgCl}_{2}$ and $\mathrm{NiCl}_{2}$ water solutions in the presence of amorphous $\mathrm{SiO}_{2}$ (aerosil A-300) by adding $400 \mathrm{ml}$ of $2 \mathrm{M} \mathrm{NaOH}$ water solution. The precipitate was washed several times with distilled water until neutral $\mathrm{pH}$ and negative results of the reaction:

$$
\mathrm{Ag}^{+}+\mathrm{Cl}^{-} \rightarrow \mathrm{AgCl} \downarrow
$$

Then the precipitate was dried at $90^{\circ} \mathrm{C}$ in air and ground in an agate mortar. Approximately 0.6 $\mathrm{g}$ of the powder was put in a stainless-steel vessel of total $400 \mathrm{ml}$ capacity, and $250 \mathrm{ml}$ of $0.5 \mathrm{M} \mathrm{NaOH}$ water solution was added as a hydrothermal medium. Hydrothermal treatment was carried out at $350^{\circ} \mathrm{C}$ and $14 \mathrm{MPa}$ during 12 hours at constant stirring. After the treatment, the product was washed several times with distilled water and then dried at $90^{\circ} \mathrm{C}$ on air.

\section{Sample Characterization}

Phase composition of samples after the co-precipitation and hydrothermal treatment was studied by the X-ray powder diffractometer (PXRD) Rigaku Smartlab SE (CuK $K_{\alpha}$ radiation $\lambda=0.15406 \mathrm{~nm}$ ). A PDF-2 database was used for peak indexing. Scanning electron microscope (SEM) FEI Quanta 200 
equipped with EDAX energy dispersive X-ray spectrometer (EDS) was used for general morphology and chemical composition analysis.

Nanoscroll structure and chemical composition features were investigated by a transmission electron microscope JEOL - ARM 200F Cold FEG operating at 200kV and equipped with a spherical aberration (CS) probe corrector (point resolution $0.19 \mathrm{~nm}$ in TEM mode and $0.078 \mathrm{~nm}$ in STEM mode) together with Gatan Digital Micrograph and JEOL Analysis Station softwares.

\section{Chemical Composition Measurements by STEM/EDS}

We obtained Ni concentration profile by performing an EDS line scan perpendicular to the nanoscroll axis, and by collecting and processing of EDS intensity maps. First approach is simpler but is more invasive for the nanoscroll than the second one. Phyllosilicate nanoscroll got burn through at each point of the line scan. EDS mapping technique also caused considerable damage to initial structure of the scroll after certain number of frames being collected, so we limited the number of frames used for further processing.

EDS intensity maps were processed involving two approaches. First, intensity map was converted to EDS quantity map using a built-in JEOL algorithm. Then Ni concentration (at.\%) normalized on sum of $\mathrm{Mg}$ and $\mathrm{Ni}$ was extracted from the desired profile perpendicular to the nanoscroll axis. In the other case, EDS intensity maps were divided into series of rectangular areas with long edges parallel to the nanoscroll axis (see Figure SI5), and Ni concentration was calculated by processing the average X-ray spectra of each area. The data obtained by these two methods was then represented versus distance from the nanoscroll central axis (distance from centre). The data points situated on equal distance to left and to the right from the nanoscroll central axis were averaged.

The Ni concentration profile obtained by this way should be further corrected, because X-ray signal comes from different layers of the nanoscroll (Figure SI1). It is assumed that apparent $\mathrm{Ni}$ concentration $C^{*}$ at $k$ layer situated at distance from centre $R_{\mathrm{k}}$ is a weighted average of true concentrations $\mathrm{Ci}$ in current and all the outer layers of effective thickness $w_{i}$ on the way of the electron beam:

$$
C_{k}^{*}=\sum_{i=1}^{k} C_{i} w_{i} / \sum_{i=1}^{k} w_{i}
$$

Effective thickness of $k$ layer has a maximum:

$$
W_{k}=2 \sqrt{2 R p-p^{2}(2 k-1)}
$$

which then drops to a constant thickness equal to $2 p$. Here $R$ is the outer radius of the scroll. The value of thickness $p$ does not have to be equal to the real phyllosilicate thickness $h$. It is determined by current magnification or number of points in line scan mode.

Assuming apparent concentration at the first (outer) layer is equal to true concentration it is possible to recalculate, going to the centre step by step (Figure SI1), $C_{k}(k=2 . . n)$ values using the equation inspired by the Abel inversion procedure:

$$
C_{k}=\frac{1}{W_{k}}\left[C_{k}^{*} \sum_{i=1}^{k} W_{l}-\sum_{i=1}^{k-1} C_{i} W_{l}\right]
$$

where $C_{\mathrm{i}}$ are true $\mathrm{Ni}$ concentrations of the layers which are outer in relation to the current one. 
This method of reconstruction has a crucial drawback related with an accumulation of error while going from the outer layers to the inner ones:

$$
\sigma C_{k} \cong \sqrt{\left(\frac{\sigma C_{k}^{*}}{W_{k}} \sum_{l=1}^{n} W_{l}\right)^{2}+\sum_{i=1}^{k-1}\left(\sigma C_{l} \frac{W_{l}}{W_{k}}\right)^{2}}
$$

\section{Acknowledgements}

The research was supported by the Russian Science Foundation grant 16-13-10252. The RXRD studies were performed using the equipment of the Engineering Centre of Saint-Petersburg State Technological Institute (Technical University). AK is grateful to Programme Metchnikov for mobility support by the Embassy of France in Russia and Campus France. AN, TB and JG are grateful to Programme Hubert Curien - Kolmogorov for mobility support through NSPH project. AN and TB benefited from the support of the project CEENEMA ANR-15-CE05-0005-01 of the French National Research Agency (ANR). 


\section{REFERENCES}

[1] G. Falini, E. Foresti, M. Gazzano, A. F. Gualtieri, M. Leoni, I. G. Lesci, N. Rovery, Chem. Eur. J. 2004, 10, 3043-3049.

[2] I. Dódony, P. R. Buseck, Int. Geol. Rev. 2004, 46, 507-527.

[3] R. Lafay, A. Fernandez-Martinez, G. Montes-Hernandez, A. L. Auzende, A. Poulain, Am. Mineral. $2016,101,2666-2676$.

[4] H. L. Zhang, X. R. Lei, C. J. Yan, H. Q. Wang, G. Q. Xiao, J. R. Hao, D. Wang, X. M. Qiu, Adv. Mater. Res. 2011, 415-417, 2206-2214.

[5] R. D. White, D. V. Bavykin, F. C. Walsh, J. Phys. Chem. C 2012, 116, 8824- 8833.

[6] L. Guimarães, A. N. Enyashin, G. Seifert, H. A. Duarte, J. Phys. Chem. C 2010, 114, 11358-11363.

[7] E. Paineau, M.-E. M. Krapf, M.-S. Amara, N. V. Matskova, I. Dozov, S. Rouzière, A. Thill, P. Launois, P. Davidson, Nat. Commun. 2016, 7, 10271.

[8] P. Picot, Y. Liao, E. Barruet, F. Gobeaux, T. Coradin, A. Thill, Langmuir 2018, 34, 13225-13234.

[9] S. lijima, Nature 1991, 354, 56-58.

[10] E. M. Pellegrino, L. Cerruti, E. M. Ghibaudi, Chem. Eur. J. 2016, 22, 4330- 4335.

[11] R. Tenne, L. Margulis, M. Genut, G. Hodes, Nature 1992, 360, 444-446.

[12] A. Polyakov, D. A. Kozlov, V. A. Lebedev, R. A. Chumakov, A. S. Frolov, L. V. Yashina, M. N. Rumyantseva, E. A. Goodilin, Chem. Eur. J. 2018, doi:10.1002/CHEM.201803502.

[13] E. Shafia, S. Esposito, M. Armandi, M. Manzoli, E. Garrone, B. Bonelli, Microporous Mesoporous Mater. 2016, 224, 229-238.

[14] S. Yu, L. Zhai, Y. Wang, X. Liu, L. Xu, L. Cheng, J. Environ. Chem. Eng. 2015, 3, 752-762.

[15] V. Bertolino, G. Cavallaro, G. Lazzara, S. Milioto, F. Parisi, Langmuir 2017, 33, 3317-3323.

[16] G. Cavallaro, A. Danilushkina, V. Evtugyn, G. Lazzara, S. Milioto, F. Parisi, E. V. Rozhina, R. F. Fakhrullin, Nanomaterials 2017, 7, 199.

[17] Yu. Lvov, W. Wang, L. Zhang, R. Fakhrullin, Adv. Mater. 2016, 28, 1227- 1250.

[18] G. Ipek Yucelen, R. E. Connell, J. R. Terbush, D. J. Westenberg, F. Dogan, Appl. Nanosci. 2015, 6, 607-614.

[19] A. A. Krasilin, I. S. Bodalyov, A. A. Malkov, E. K. Khrapova, T. P. Maslennikova, A. A. Malygin, Nanosyst. Phys. Chem. Math. 2018, 9, 410-416.

[20] M. Zhu, J. Lan, C. Tan, G. Sui, X. Yang, J. Mater. Chem. A 2016, 4, 12136- 12143.

[21] Y. Liao, P. Picot, J.-B. Brubach, P. Roy, S. Le Caër, A. Thill, Appl. Clay Sci. 2017, 164, 58-67.

[22] S. Piperno, I. Kaplan-Ashiri, S. R. Cohen, R. Popovitz-Biro, H. D. Wagner, R. Tenne, E. Foresti, I. G. Lesci, N. Roveri, Adv. Funct. Mater. 2007, 17, 3332-3338.

[23] B. Lecouvet, J. Horion, C. D'Haese, C. Bailly, B. Nysten, Nanotechnology 2013, 24, 105704. 
[24] E. Borghi, M. Occhiuzzi, E. Foresti, I. G. Lesci, N. Roveri, Phys. Chem. Chem. Phys. 2010, 12, 227238.

[25] A. A. Krasilin, A. S. Semenova, D. G. Kellerman, V. N. Nevedomsky, V. V. Gusarov, EPL 2016, 113, 47006.

[26] Z. Bian, I. Y. Suryawinata, S. Kawi, Appl. Catal. B 2016, 195, 1-8.

[27] J. Ashok, Z. Bian, Z. Wang, S. Kawi, Catal. Sci. Technol. 2018, 8, 1730- 1742.

[28] A. Bloise, E. Belluso, E. Barrese, D. Miriello, C. Apollaro, Cryst. Res. Technol. 2009, 44, 590-596.

[29] A. A. Krasilin, A. M. Suprun, V. V. Gusarov, Russ. J. Appl. Chem. 2013, 86, 1633-1637.

[30] A. Bloise, E. Belluso, E. Fornero, C. Rinaudo, E. Barrese, S. Capella, Microporous Mesoporous Mater. 2010, 132, 239-245.

[31] T. P. Maslennikova, E. N. Korytkova, Glass Phys. Chem. 2013, 39, 67-72.

[32] A. A. Krasilin, V. N. Nevedomsky, V. V. Gusarov, J. Phys. Chem. C 2017, 121, 12495-12502.

[33] A. Bloise, E. Barrese, C. Apollaro. N. Jb. Miner. Abh. 2009, 185, 297-304.

[34] T. P. Maslennikova, E. N. Gatina, Russ. J. Appl. Chem. 2018, 91, 286-291.

[35] R. Perbost, M. Amouric, J. Olives, Clays Clay Miner. 2003, 51, 430-438.

[36] A. Thill, B. Guiose, M. Bacia-Verloop, V. Geertsen, L. Belloni, J. Phys. Chem. C 2012, 116, 2684126849.

[37] E. Shafia, S. Esposito, M. Manzoli, M. Chiesa, P. Tiberto, G. Barrera, G. Menard, P. Allia, F. S. Freyria, E. Garrone, B. Bonelli, J. Nanopart. Res. 2015, 17, 336.

[38] A. Bloise, E. Barrese, C. Apollaro, D. Miriello, Cryst. Res. Technol. 2009, 44, 463-468.

[39] A. A. Krasilin, A. M. Suprun, V. N. Nevedomsky, V. V. Gusarov, Dokl. Phys. Chem. 2015, 460, 4244.

[40] A. A. Krasilin, V. V. Gusarov, Nanosyst. Phys. Chem. Math. 2017, 8, 620-627.

[41] A. A. Krasilin, A. M. Suprun, E. V. Ubyivovk, V. V. Gusarov, Mater. Lett. 2016, 171, 68-71.

[42] A. A. Krasilin, V. V. Gusarov, Tech. Phys. Lett. 2016, 42, 55-58.

[43] S. Zhang, Q. Chen, L.-M. Peng, Phys. Rev. B 2005, 71, 014104.

[44] A. N. Enyashin, G. Seifert, Phys. Status Solidi 2005, 242, 1361-1370.

[45] K. Momma, F. Izumi, J. Appl. Crystallogr. 2011, 44, 1272-1276.

[46] E. J. W. Whittaker, Acta Crystallogr. 1956, 9, 855-862.

[47] B. A. Cressey, E. J. W. Whittaker, Mineral. Mag. 1993, 57, 729-732.

[48] R. Demichelis, M. De La Pierre, M. Mookherjee, C. M. Zicovich-Wilson, R. Orlando, CrystEngComm 2016, 18, 4412-4419.

[49] R. Lafay, G. Montes-Hernandez, E. Janots, R. Chiriac, N. Findling, F. Toche, Chem. Eur. J. 2013, 19, 5417-5424. 
[50] V. K. Ivanov, P. P. Fedorov, A. Y. Baranchikov, V. V. Osiko, Russ. Chem. Rev. 2014, 83, 1204-1222.

[51] R. D. White, D. V. Bavykin, F. C. Walsh, J. Mater. Chem. A 2013, 1, 548- 556.

[52] F. Alvarez-Ramírez, J. A. Toledo-Antonio, C. Angeles-Chavez, J. H. Guerrero-Abreo, E. LópezSalinas, J. Phys. Chem. C 2011, 115, 11442- 11446. 

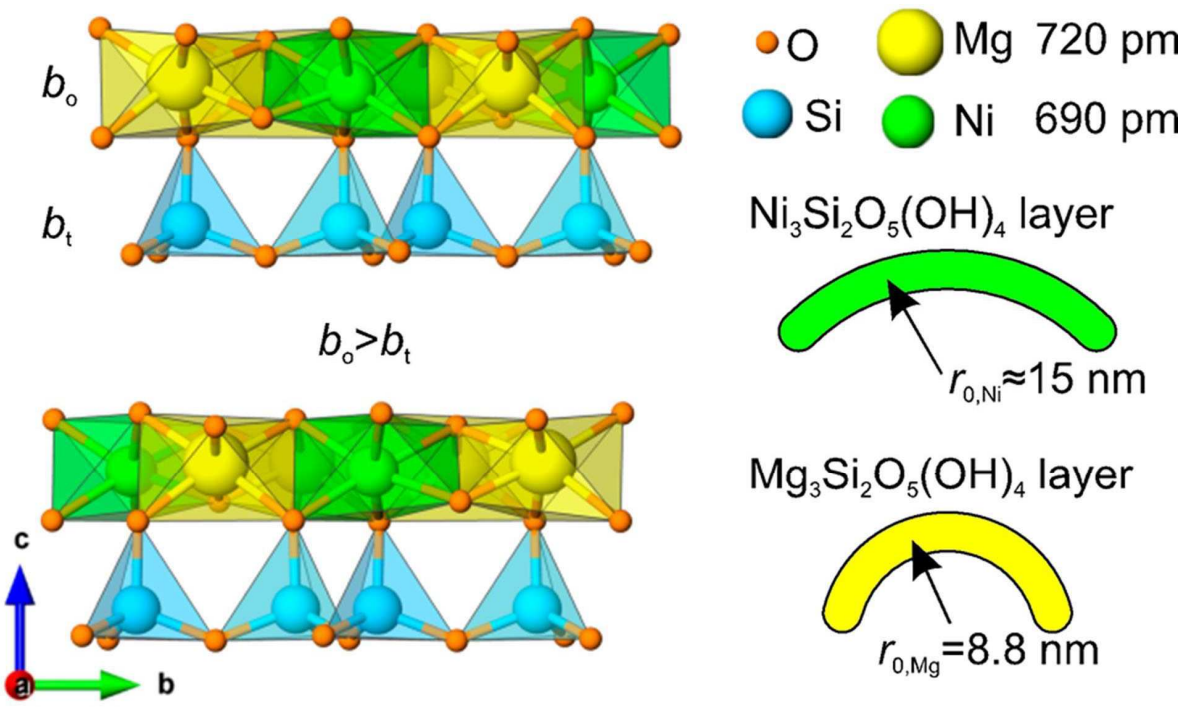

$\mathrm{Mg}_{3} \mathrm{Si}_{2} \mathrm{O}_{5}(\mathrm{OH})_{4}$ layer

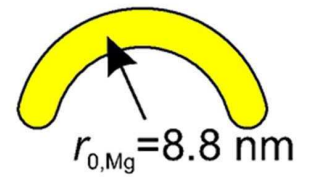

Figure 1. Crystal structure of Ni-doped chrysotile based the data of Foresti et al.[1] Visualization was made using VESTA 3 software. [45] Bending of the layer is caused by size difference between octahedral and tetrahedral sheets. Preferable radius of curvature is influenced by ionic radii of constituting cations. 


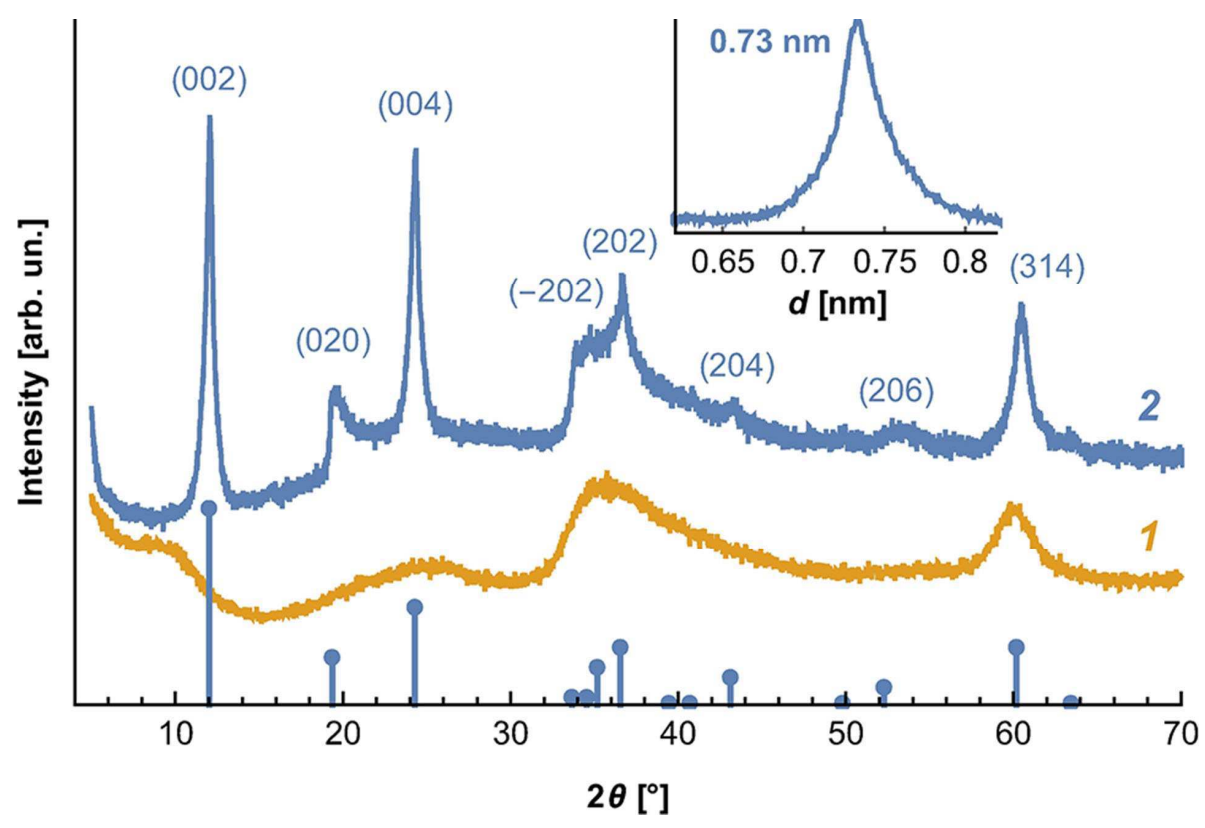

Figure 2. PXRD patterns of initial composition (1) and its hydrothermal treatment product (2). Vertical lines represent chrysotile phase (card \#10-381, PDF-2 database). Inset shows first reflection (002) of hydrosilicate phase with a maximum at $0.73 \mathrm{~nm}$. 

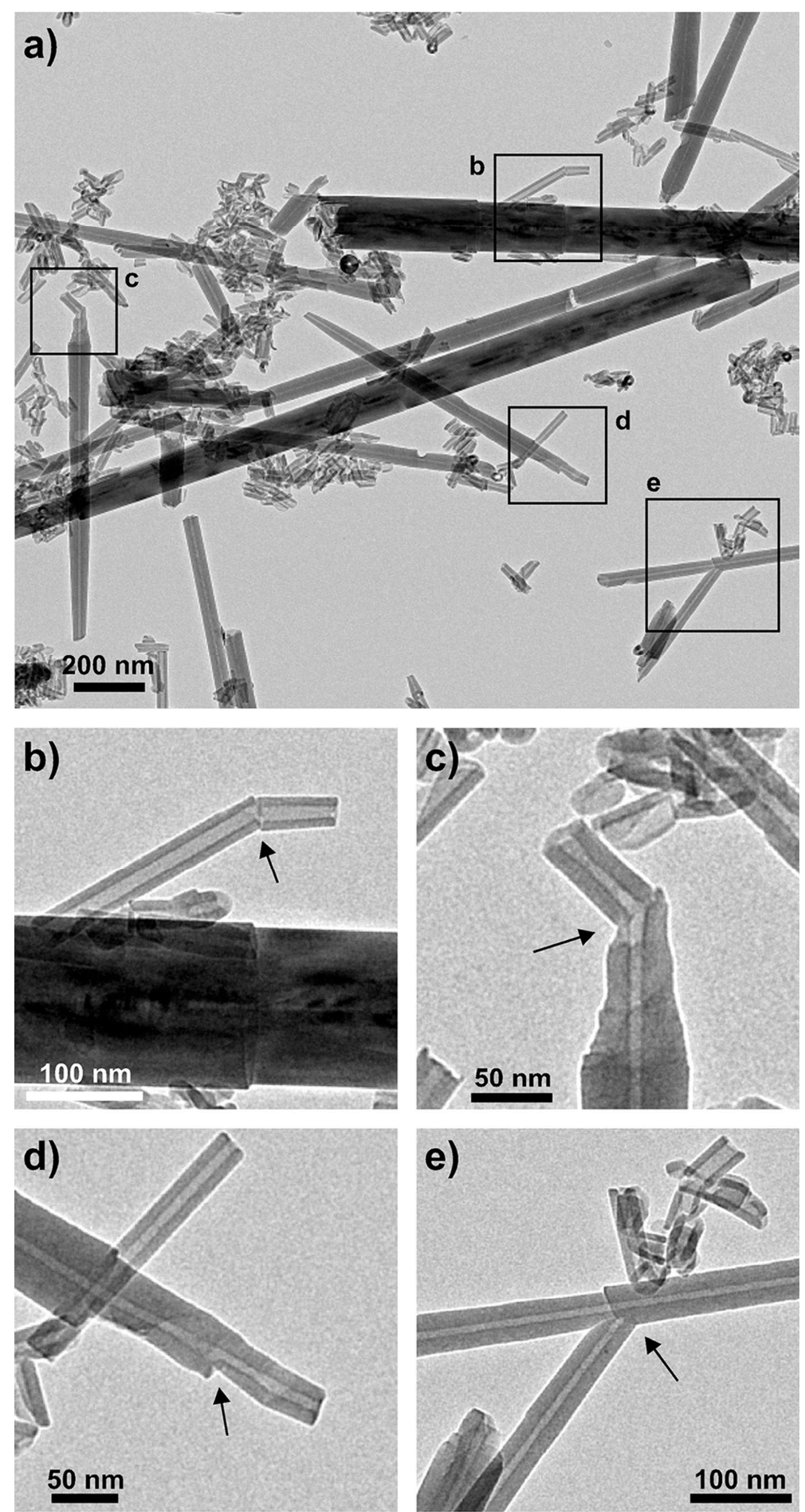

Figure 3. a) TEM image of ( $\mathrm{Mg}, \mathrm{Ni}) 3 \mathrm{Si} 2 \mathrm{O} 5(\mathrm{OH}) 4$ nanoscrolls. b-e) Magnified fragments of the TEM image. The arrows denote particles, which probably have grown involving an attachment mechanism. 

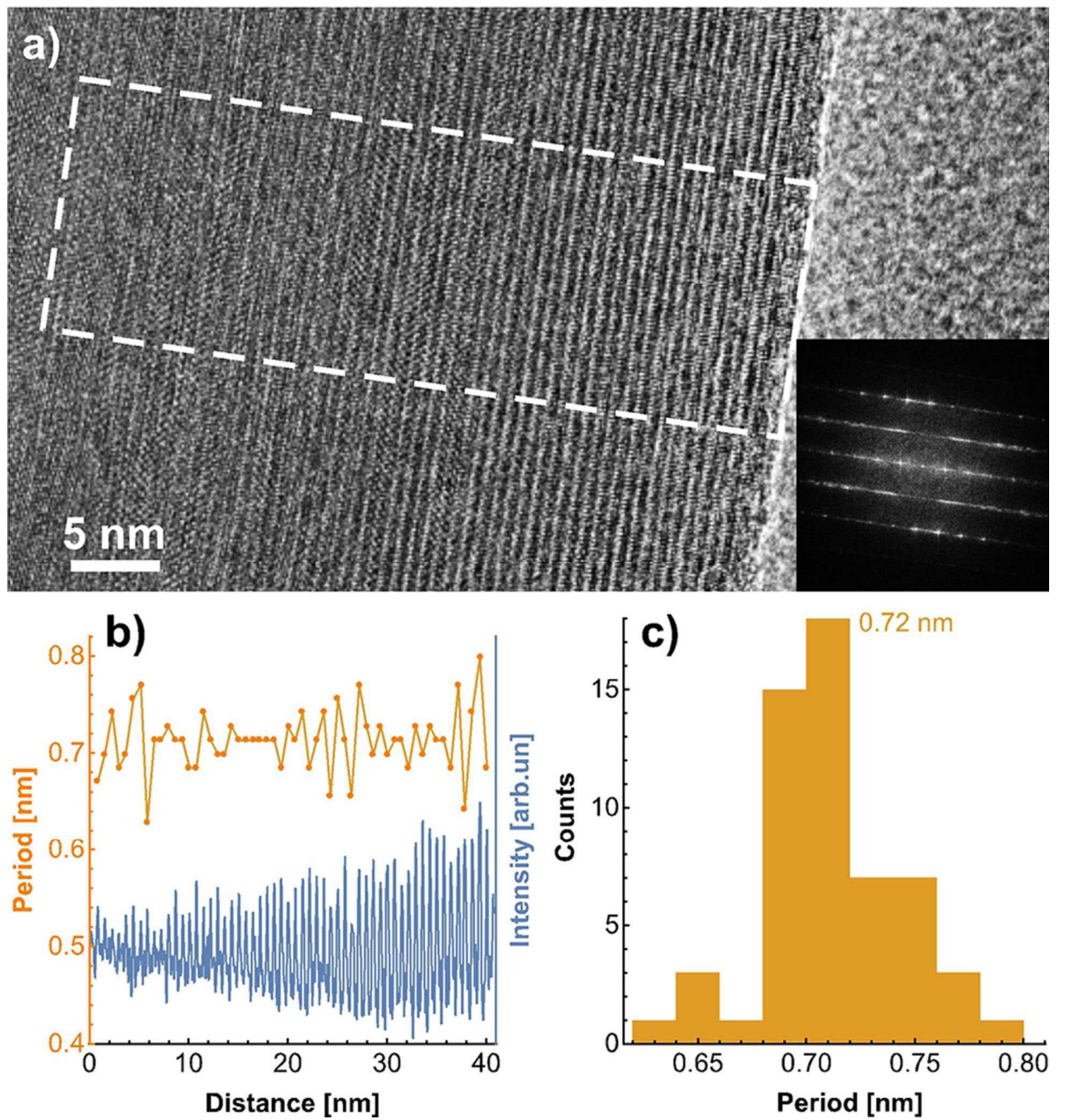

Figure 4. a) TEM image of the nanoscroll wall. Area of inspection is shown by rectangle. b) A grey value profile of the area averaged parallel to the layers. Dots denote change of the interlayer period with distancing from the nanoscroll centre. $c$ ) Distribution of the interlayer period with a maximum at 0.72 $\mathrm{nm}$. 


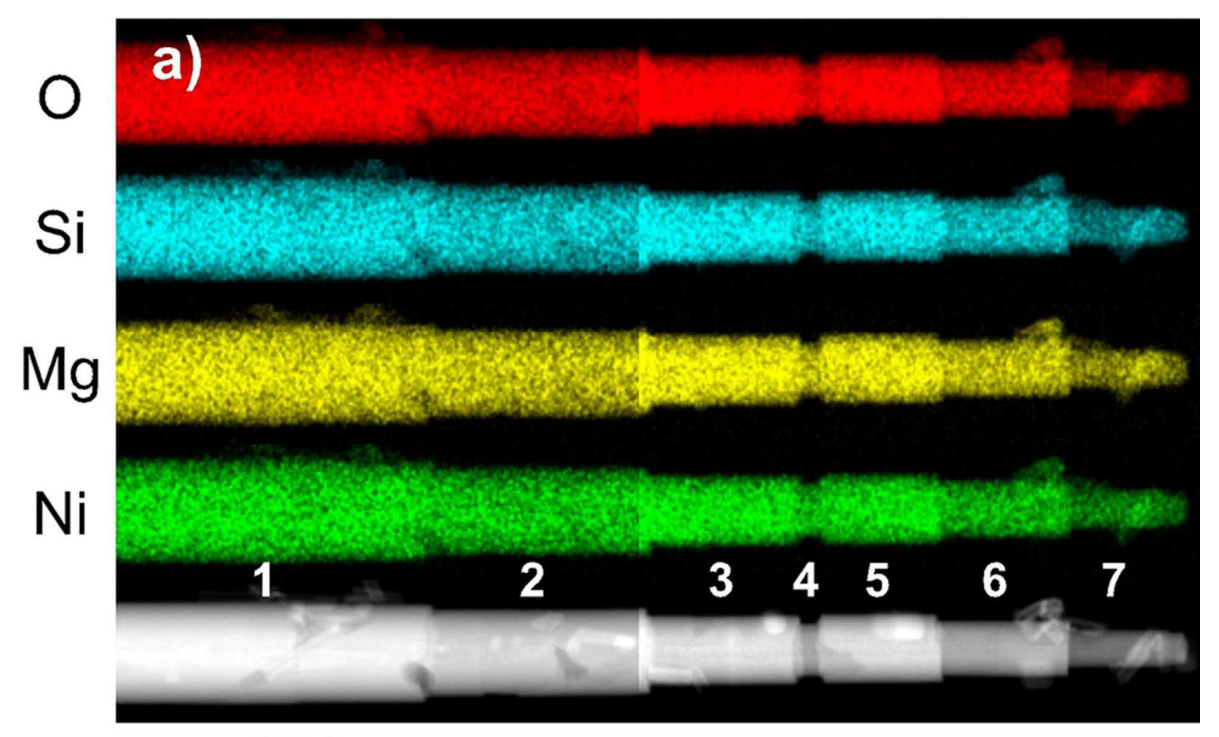

$200 \mathrm{~nm}$

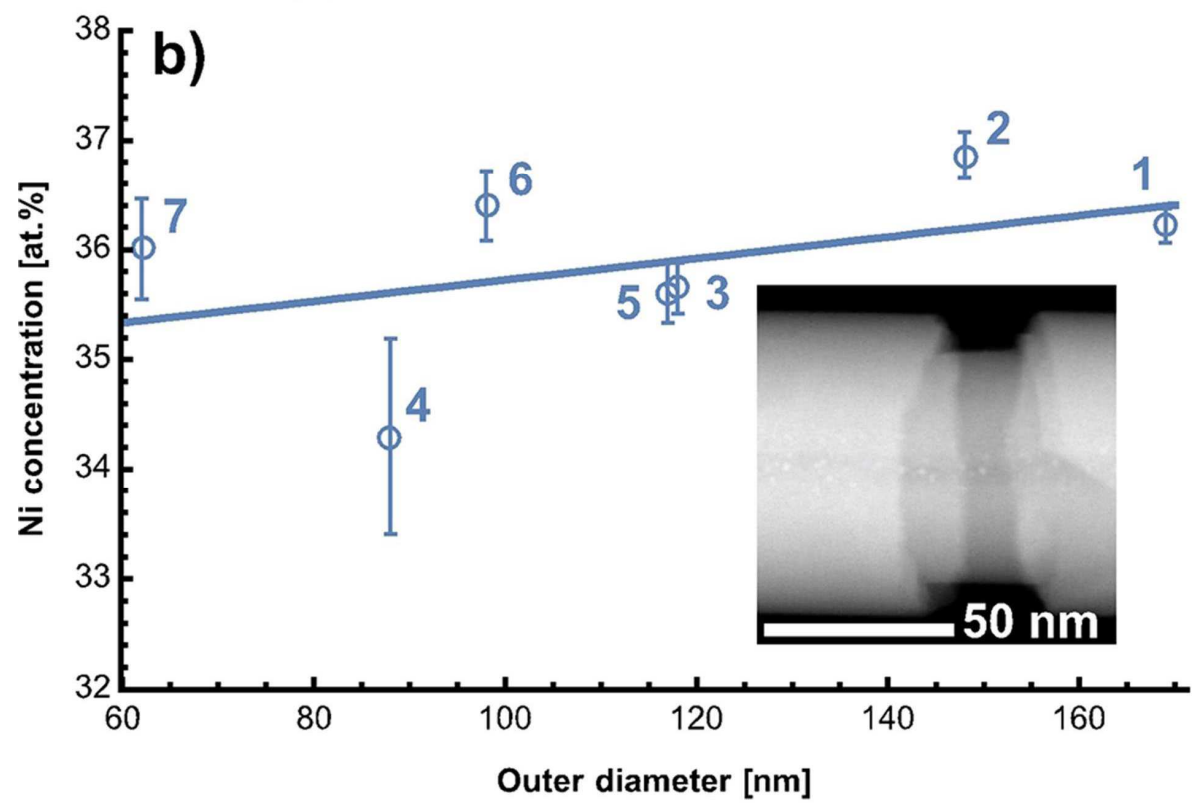

Figure 5. a) STEM image of telescopic particle and its EDS mapping (composed of two frames). The numbers denote areas, at which $\mathrm{Ni}$ concentration was averaged. b) Ni concentration at different areas of the nanoscroll in comparison with its outer diameter. The inset shows magnified STEM image of the area \#4. 

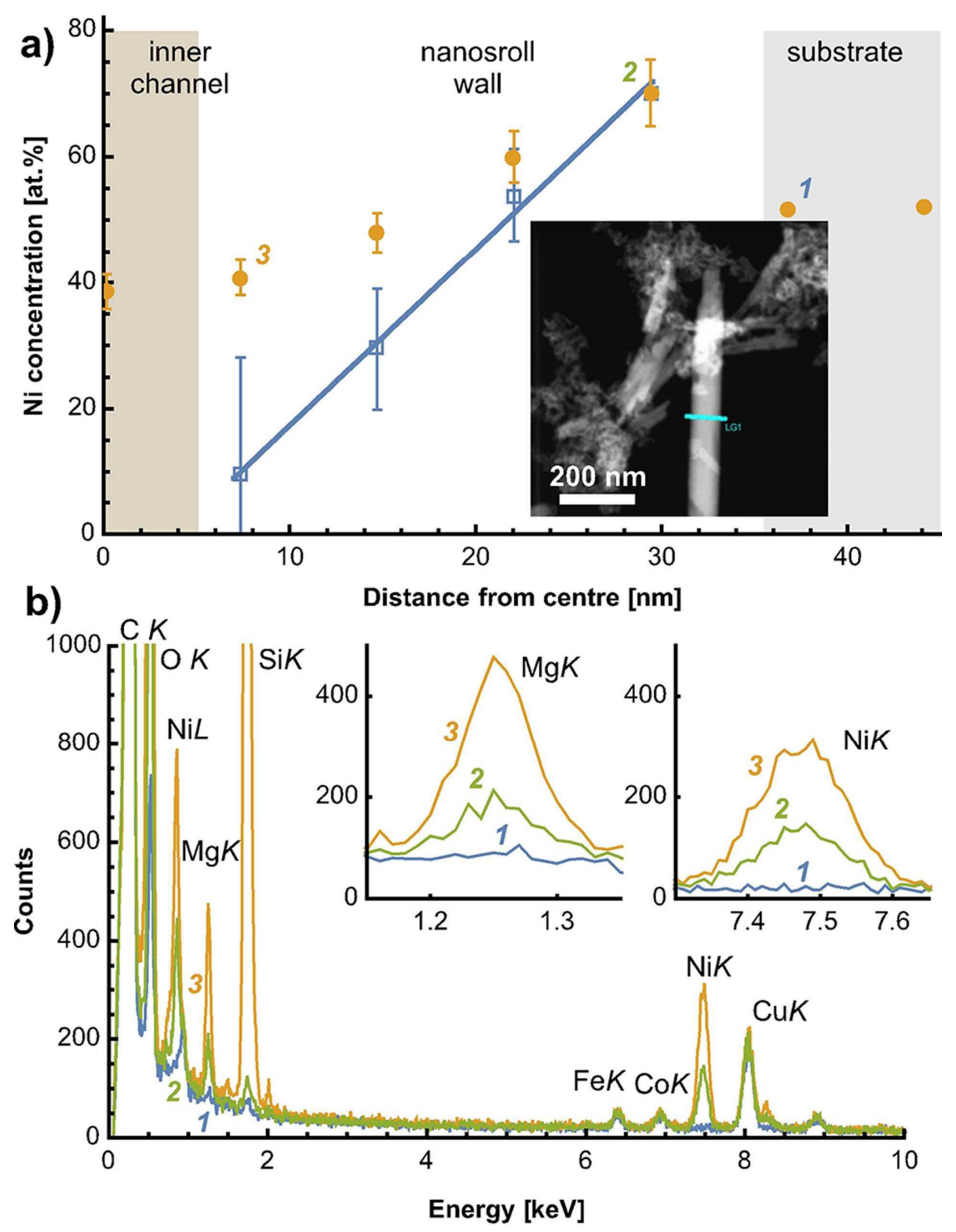

Figure 6. a) Change of apparent (solid circles) and reconstructed (hollow squares) Ni concentration with increase of distance from the nanoscroll centre. Inset shows STEM image of the nanoscroll and position of the line scan (large STEM image is available on Figure SI2). Mean value of apparent concentration is 53 at.\% b) X-ray spectra in points situated near the nanoscroll (1), on the outer surface (2), and near the inner channel (3). Insets show MgK and NiK lines. 


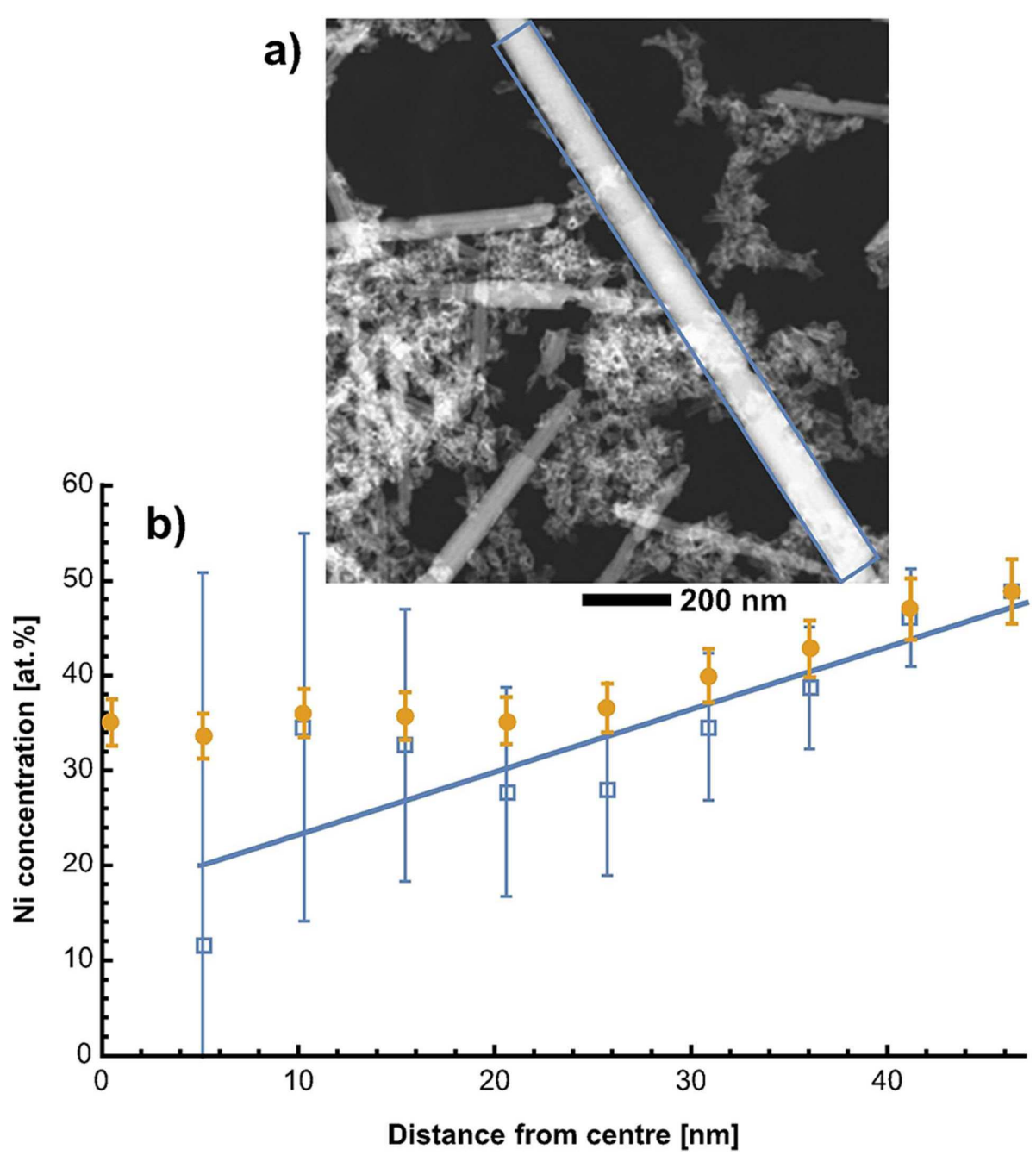

Figure 7. a) STEM image of the nanoscroll. Apparent $\mathrm{Ni}$ concentration was calculated along the line perpendicular to the nanoscroll axis, and spectra were averaged along the wide edge of selected rectangular area (large scale image is shown on Figure SI3). Mean value of apparent concentration is 39 at.\% b) Change of apparent (solid circles) and reconstructed (hollow squares) Ni concentration with increase of distance from the nanoscroll centre. 


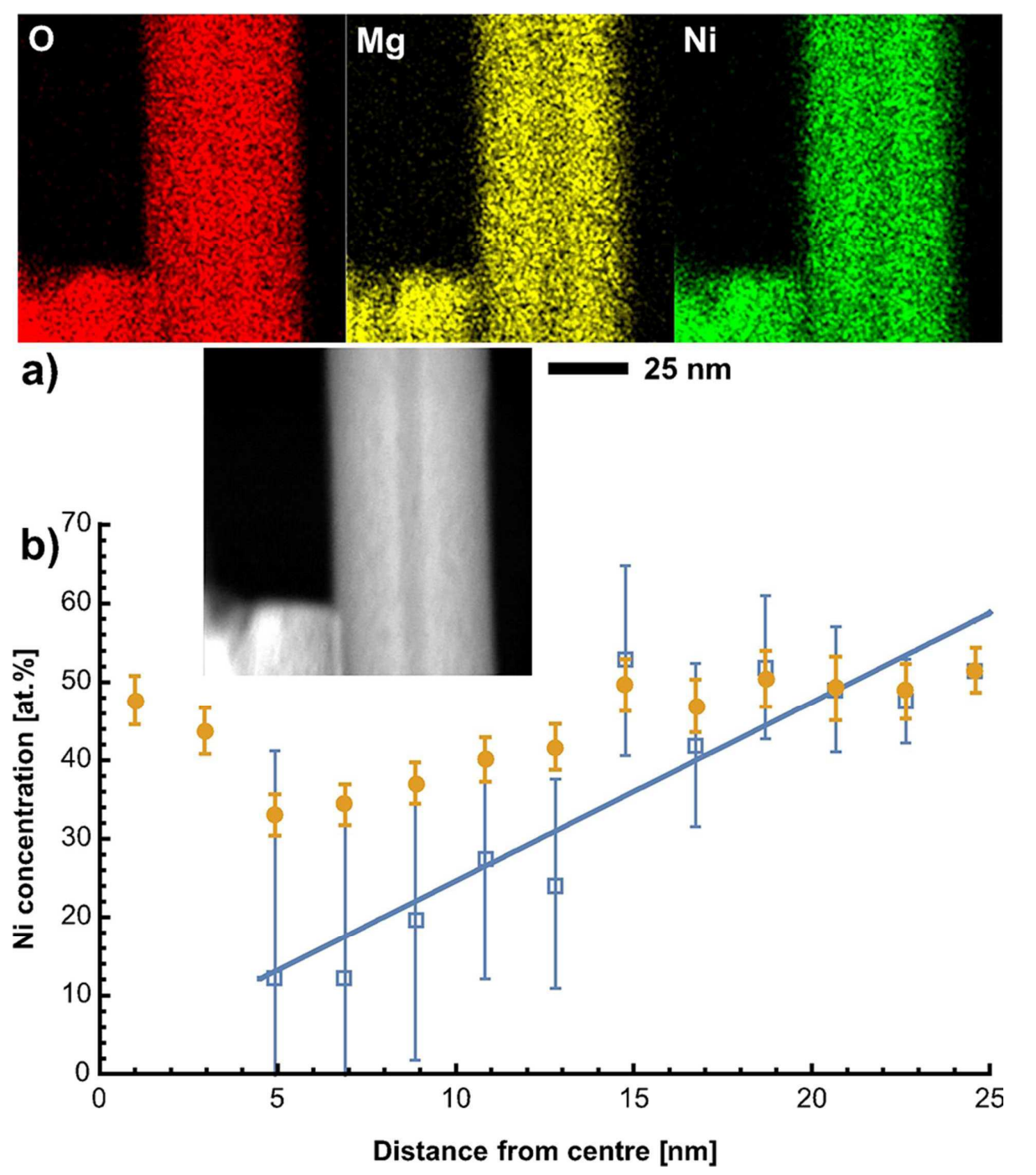

Figure 8. a) STEM image and EDS maps of the nanoscroll (for details on how spectra were obtained please see Figure SI5). Average apparent Ni concentration is 44 at.\% b) Change of apparent (solid circles) and reconstructed (hollow squares) Ni concentration with increase of distance from the nanoscroll centre. 


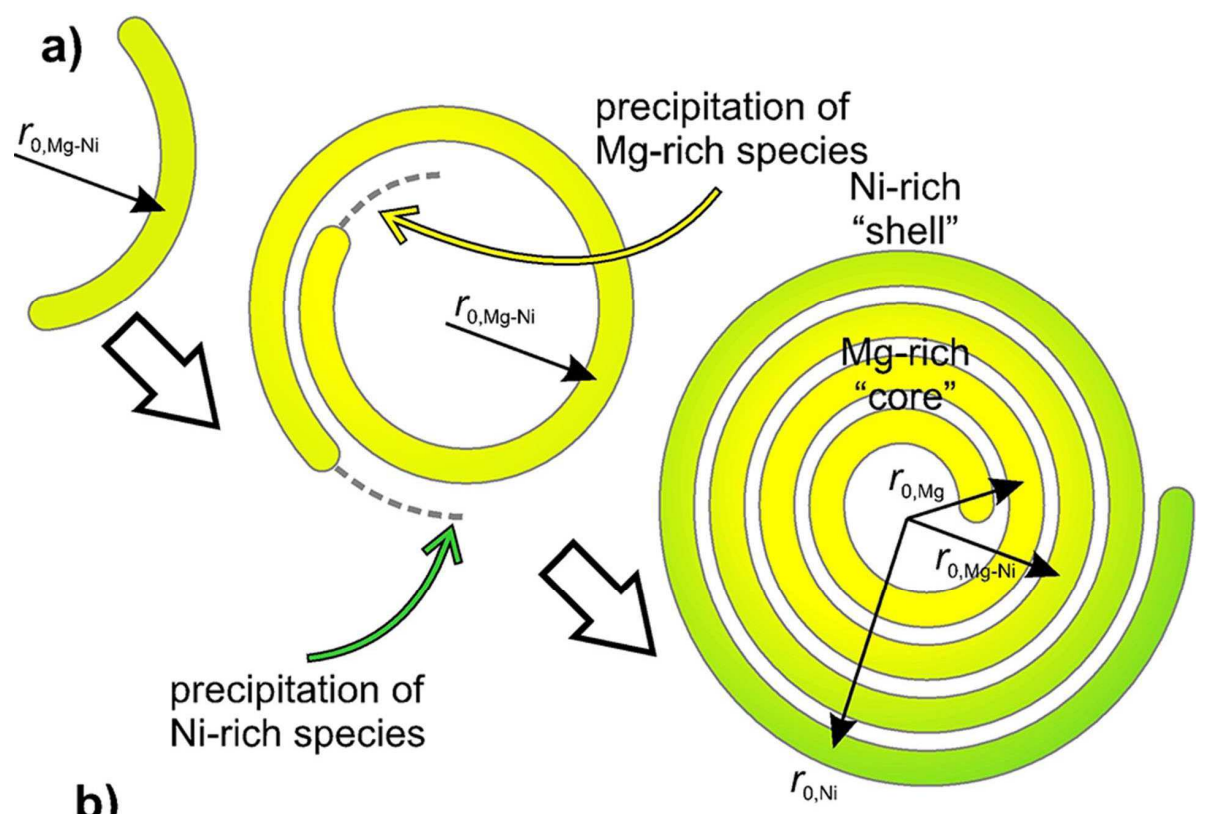

b)

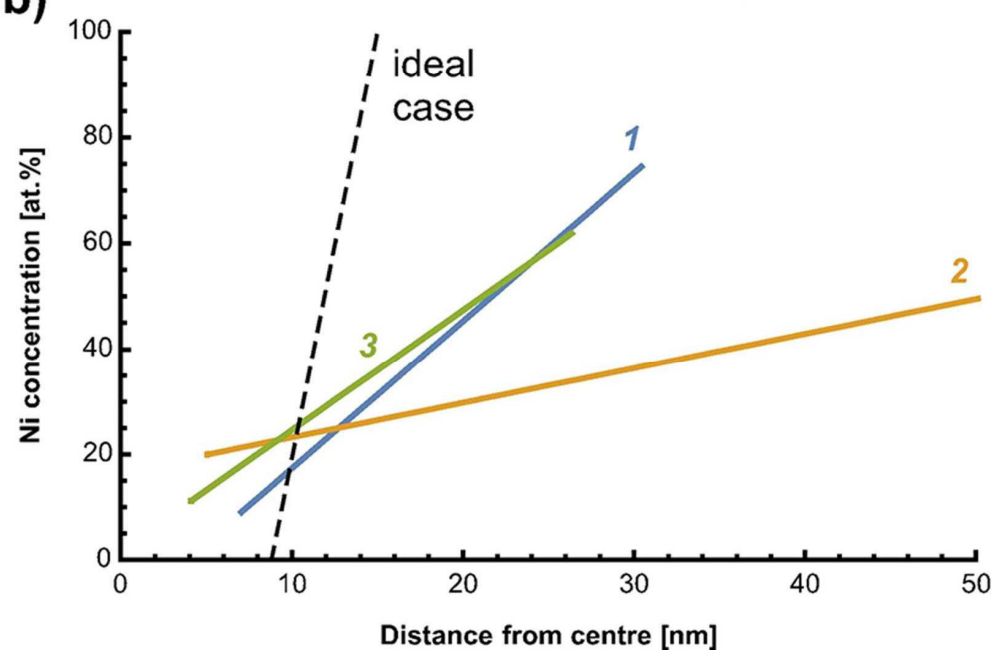

Figure 9. a) Possible mechanism of $\mathrm{Mg} 2+$ and $\mathrm{Ni2}+$ cations redistribution as a result of the nanoscroll growth process. b) Results of linear regression of the data represented on Figure 6a (line 1), Figure 7b (line 2), and Figure 8b (line 3 ) in comparison with maximal gradient (dashed line), predicted by the equation (9). 
Table 1. Element concentrations [at.\%] measured by conventional SEM/ EDS.

\begin{tabular}{|llllll|}
\hline $\mathrm{O}$ & $\mathrm{Mg}$ & $\mathrm{Si}$ & $\mathrm{Ni}$ & $R^{[a]}$ & $C_{\mathrm{Ni}}^{[\mathrm{b}]}$ \\
\hline $56.4 \pm 2.2$ & $12.2 \pm 1.0$ & $16.7 \pm 1.4$ & $14.7 \pm 1.1$ & $1.6 \pm 0.2$ & $54.6 \pm 5.5$ \\
\hline [a] $R=(\mathrm{Mg}+\mathrm{Ni}) / \mathrm{Si} .[\mathrm{b}]$ & $C_{\mathrm{Ni}}=100 \mathrm{Ni} /(\mathrm{Mg}+\mathrm{Ni})$ & & \\
\hline
\end{tabular}

